Milijana Lazarević

Visoka škola strukovnih studija za vaspitače „Mihailo Palov“ Vršac

Marija Malovićz

Visoka škola strukovnih studija za vaspitače „Mihailo Palov“

Vršac
Original scientific paper

UDK: 371.695

DOI: $10.5937 /$ IstrPed2101278L

\title{
PRAKSA KUPOVINE DEČIJIH IGRAČAKA IZ UGLA ODRASLIH
}

Rezime: Ovaj rad bavi se istraživanjem praksi kupovine igračaka za decu kroz prizmu promišljanja o ulozi igračaka u učenju i razvoju dece i uticaju komercijalizacije detinjstva na ponudu i odabir igračaka kojima će se deca igrati sa fokusom na preispitivanje uloge odraslih u oblikovanju dečjeg okruženja za igru posredstvom igračaka. $U$ radu je predstavljeno istraživanje eksplorativnog karaktera sprovedeno putem online ankete na uzorku od 112 učesnika sa ciljem sagledavanja i opisivanja prakse kupovine dečjih igračaka od strane odraslih. Istraživanje je tragalo za odgovorom na pitanje šta određuje praksu kupovine igračaka za decu, kao i koji su to elementi prakse kupovine igračaka za decu koji utiču na izbor prilikom kupovine. Rezultati pokazuju da odrasli često kupuju igračke za decu (60\% učesnika istraživanja ih kupuje jednom u tri meseca ili češće). Kao najčešći povod za kupovinu igračaka izdvajaju se dečji rođendani. lako odrasli kupuju igračke sa namerom da one dugo traju i da se nasleđuju (34\%), u praksi se deca njima najčešće igraju par meseci (31\%) ili tek neposredno nakon što igračku dobiju ( $25 \%$ ). U potrazi za dobrom igračkom za decu odrasli tragaju za onom koja će na prvom mestu detetu biti zanimljiva, ali i onom koja će podržavati kreativni pristup igri i podsticati dečji razvoj i učenje.

Ključne reči: igra, igračke, potrošačko društvo, podrška dečjoj igri, kupovina igračaka, igračka kako poklon, upotrebna vrednost igračaka, koncept dobre igračke.

\section{Uvod}

Dvadeseti vek predstavlja specifični period u pogledu kulture odrastanja u razvijenim zemljama, jer u ovom veku kupovina i upotreba komercijalnih proizvoda postaje značajan aspekt dečjeg iskustva, te deca postaju jedna od najciljanijih potrošačkih grupa (Korsvold, 2010). Zato dvadeseti vek nije samo 'vek deteta' (Key, 2000; prema: Petrovic, 2015), jer danas sa sigurnošću možemo reći da on predstavlja i "vek deteta potrošača” (Cook, 2004; prema Korsvold, 2010) kao socijalne konstrukcije koja odražava skup verovanja i pretpostavki o načinima na koje deca konzumiraju komercijalne proizvode (Cook, 2007). Kako tvrde mnogi teoretičari kulture i ranog obrazovanja (Buckingham \& Tingstad, 2007; Kapur, 2005; Kincheloe, 2011; Olfman, 2009; prema: Pavlović Breneselovic \& Krnjaja, 2016) živimo u doba visoko

\footnotetext{
${ }^{1}$ milijana.lazarevic1@gmail.com

²m.malovic@outlook.com
} 
komercijalizovanog detinjstva, koje se između ostalog ogleda i kroz masovnu upotrebu dečjih igračaka kao proizvoda namenjenih deci.

Igračke predstavljaju jednu vrstu predmeta materijalne prirode koji deca koriste u igri. One se razlikuju od realnih predmeta ${ }^{3}$ i nestrukturiranih materijala ${ }^{4}$ koje deca takođe mogu koristiti u igri, po tome što su igračke predmeti kreirani od strane odraslih sa jasnom namenom - da se deca njima igraju. lako se deca mogu igrati gotovo svakim objektom, igračke su uvek zauzimale posebno mesto u odrastanju deteta, jer su one za razliku od drugih objekata specijalno dizajnirane upravo za decu (Bergen, 2018).

U ovom radu fokus će biti upravo na gotovim igračkama i iskustvima njihove kupovine, jer istraživanja pokazuju da su deca danas mnogo više izložena gotovim igračkama nego što imaju mogućnosti igre nestrukturiranim materijalima i realnim predmetima (Dauch, Imwalle, Ocasio \& Matz, 2018). Igračke su više od objekata za dečiju igru (Cross, 2004). One takođe služe i kao medijatori poruka namenjenih deci o tome šta odrasli očekuju od njih, kakav sistem vrednosti neguju i žele da i deca usvoje te vrednosti, kako igra treba da izgleda, stoga se mogu smatrati bitnim posrednikom u vaspitaju dece.

\section{Uloga igračaka u dečjem razvoju i učenju}

Značaj igre u ranom detinjstvu i njen doprinos dečjem razvoju i učenju tema je koja ne gubi na aktuelnosti već decenijama, naprotiv - sve je više istraživanja u različitim naučnim disciplinama koja se bave ovom temom.

Igra je veoma moćan i važan "sastojak" odrastanja jer u igri dete transformiše svet po vlastitoj meri, a sebe strukturira i adaptira sledeći ovu transformaciju (Marjanovic, 1979). To znači da u igri deca prevazilaze granice mogućeg, zamišljaju, maštaju, a zatim menjajući svoje okruženje i svoje ponašanje stvaraju ono što ne postoji. U tim trenucima deca funkcionišu na dva "plana" realnom i imaginarnom. Na realnom planu deca su svesna da to čega se trenutno igraju nije stvarno. Međutim, ta zamišljena stvarnost ih ne sprečava da zaista doživljavaju i proživljavaju ono čega su zamislili da se igraju.

Ovo svojstvo igre, da podstakne dete da funkcioniše i u zamišljenoj i u realnoj stvarnosti pokreće kapacitet fleksibilnosti - ukupan potencijal ljudskog bića za promenu (Krnjaja, 2012b). Kapacitet fleksibilnosti svojstven je samo ljudskim bićima, i omogućava nam da zamislimo nešto sto ne postoji, a onda to u stvarnosti i stvorimo. Time mi možemo menjati uslove življenja, usklađivati sebe i svoje ponašanje u odnosu na ove promenjene uslove i tako ciklično menjati svoje okruženje i prilagođavati se novim okolnostima. Kapacitet fleksibilnosti možemo razumeti i kao osnov svih pronalazaka na svetu, jer bez postojanja ovog kapaciteta mi ne bismo imali mogućnost da transformišemo stvarnost u odnosu na zamišljeno.

Kada ovako sagledamo igru, razumemo da ona zauzima veoma važno mesto u procesu dečjeg razvoja i učenja. A kako danas u savremenoj kulturi igračke zauzimaju veoma važno mesto u životu deteta, jer već od prvih dana njegovog života odrasli ga okružuju igračkama sa jasnim

3Predmeti iz okruženja koji nisu kreirani za potrebe igre (na primer posuđe, telefon, delovi garderobe odraslih itd) ali se deca ipak njima igraju.

${ }^{4}$ Materijali iz prirode (gračnice, kamenje, pesak, školjke, šišarke itd) i reciklažni materijali koje deca koriste u igri. 
predstavama o njihovoj ulozi u detetovom razvoju i učenju, potrebno je otvoriti pitanje prakse kupovine i odabira igračaka iz ugla odraslih.

Izgled, namena i funkcije igračaka menjali su se kroz istoriju, odražavajući time i promenu stavova odraslih prema deci i igri (Saton-Smith, 1989), jer kultura igračaka je prvenstveno kultura odraslih a tek potom kultura deteta (Krnjaja, 2012b: 123). Kažemo da igračke pripadaju kulturi odraslih zbog toga što su u savremenom svetu odrasli ti koji kreiraju igračke (a ne deca kojoj su one namenjene). Time su igračke oblikovane očekivanjima koja odrasli imaju kako u odnosu na igračku i njen doprinos dečjem razvoju i učenju, tako i u odnosu na dete i načine na koje će ono igračku koristiti.

Popularnu dečju kulturu koja obuhvata igračke, igre, medije i nove tehnologije, neki istraživači smatraju opasnošću za kulturnu raznolikost dečje igre (Marsh et al. 2005; prema: Krnjaja, 2012a). Pomenutu opasnost prepoznajemo u praksi da gotove igračke istiskuju nestruktuirane materijale iz dečje igre, iako se nestruktuirani materijali smatraju onim materijalima koji u najvećoj meri podržavaju dečju simboličku i stvaralačku igru, jer pružaju raznolikost u igri zbog širokog raspona različitih tekstura, boja, oblika i veličina i predstavljaju bogat izvor senzornih informacija (Krnjaja, 2012b).

Pitanje uticaja igračaka na građenje dečje igre i načina na koje ona grade predstave o svetu posredstvom igračaka sve je češće u fokusu različitih istraživanja. Tako je istraživanje sprovedeno sa decom jaslenog uzrasta pokazalo da kod one dece koja u svom okruženju imaju manje igračaka igra će duže trajati, kod dece će biti primetan bolji fokus u igri koji ih pokreće da koriste svoje kreativne potencijale i da eksperimentišu, dok će veći broj igračaka u okruženju negativno uticati na kvalitet igre (Dauch, Imwalle, Ocasio \& Matz, 2018). U skladu sa ovim nalazima su i oni da deca radije biraju realne predmete i nestrukturirane materijale u igri nego gotove igračke (Celebi Oncu \& Unluer, 2010), ali uprkos tome mi ne možemo zanemariti trend masovne kupovine igračaka deci već od prvog dana života, koji iz godine u godinu postaje sve prisutniji. Da bismo razumele zbog čega su deca danas okružena sve većim brojem igračaka u nastavku ćemo ovu pojavu sagledati kroz prizmu komercijalizacije detinjstva.

\section{Komercijalizacija detinjstva i razvoj tržišta igračaka za decu}

Kada kažemo da je danas detinjstvo u velikoj meri komercijalizovano to znači da na tržištu možemo naći širok spektar proizvoda namenjenih deci, te da industrija usmerena na proizvode za decu zalazi u mnoge aspekte detinjstva - od toga kako se deca oblače, čime se hrane, koje sadržaje čitaju i gledaju, kako se igraju (Williams, 2007). Materijalizacija dečjih života najizraženija je na polju dečje igre, usled jačanja industrije igračaka za decu (Kline, 1993) koja je u najvećoj meri uticala na komercijalizaciju detinjstva. Period šezdesetih godina prošlog veka prepoznat je kao prekretnica u kojoj je industrija igračaka napustila trend proizvodnje igračaka koje se nasleđuju i prešla na njihovu masovnu proizvodnju (Gross, 1997).

Igračke su proizvodi namenjeni deci, a deca su značajna potrošačka grupa jer se njihov "tržišni potencijal" može razložiti na više nivoa: ona predstavljaju "primarne potrošače", kojima se direktno plasiraju produkti njima namenjeni, ali i "uticajne potrošače", koji mogu doprineti tome da odrasli ulažu svoj novac u kupovinu proizvoda za decu, dok su takođe i "potrošači budućnosti” kod kojih još u detinjstvu treba stvoriti potrošačke navike (McNeal, 2000). Za nas u ovom radu najznačajnija je analiza nivoa "uticajnog potrošačkog potencijala" jer se mi bavimo preispitivanjem prakse kupovine igračaka iz ugla odraslih. 
Polje marketinga i plasiranja proizvoda sastavni je deo fenomena komercijalizacije i na ovom polju dešava se borba proizvođača na tržištu. Različitim marketinškim poduhvatima svi oni se bore da potrošač odabere baš njihov proizvod u mnoštvu ponude. Usled marketinškog pritiska kojima su odrasli izloženi kako direktno tako i indirektno (jer su neke reklamne kampanje usmerene direktno na decu kao potrošački "uticajnu” grupu), kao i usled ustaljene prakse da se igračke poklanjaju deci u različitim prilikama odrasli često imaju dileme koji kriterijum izbora napraviti pri kupovini igračaka. Rešenje ovog problema može biti razvijanje potrošačke pismenosti koja se ogleda u veštinama i znanju potrebnim da bi se razumeo komercijalni svet i da bi se u njemu postupalo na autonoman način (DCSF \& DCMS, 2007).

Kako deca danas odrastaju u potrošačkom društvu i od ranog detinjstva su deo "tržišnoposredovane kulture” (Kline, 1993) koja predstavlja specifično simboličko okruženje, potrebno je stalno preispitivanje na koji način komercijalizacija oblikuje detinjstvo. Biti deo potrošačkog društva podrazumeva konstantno prisustvo različitih brendova u našim životima, a neretko sa sobom nosi građenje identiteta posredstvom brendova - kada se opredelimo za neki brend mi se identifikujemo sa vrednostima koje on predstavlja (Malovic, 2019). Pored toga, prekomerna izloženost efektima komercijalizacije razvija osobinu materijalizma i potrebu za konzumiranjem, dečje potrebe i želje usmeravaju se u velikoj meri na materijalna dobra (Piachaud, 2007) pa dolazi do toga da se sistem vrednosti kreira spram tržišnih vrednosti, te počinjemo da verujemo da je ono što više košta samim tim i vrednije (Malovic, 2019). Mladi, a posebno deca ranog uzrasta, u društvu koje usled komercijalizacije detinjstva postaje za njih sve otuđenije procenjuju svoju važnost i ulogu kroz prizmu onoga što poseduju (Milisa i Spasenovski, 2017).

\section{Uloga odraslih u oblikovanju dečjeg okruženja za igru posredstvom igračaka}

Uloga odraslih u oblikovanju prostora u kome deca borave i u kome se igraju (u ovom slučaju porodični prostori) nije često bila tema pedagoških istraživanja, ali ukoliko znamo da način na koji se odrasli odnose prema ovom pitanju direktno oslikava njihove stavove prema deci i igri (Saton-Smith, 1989) razumećemo i značaj otvaranja ove teme iz pedagoške perspektive.

Odrasli direktno utiču na oblikovanje dečjeg okruženja za igru time što i pre detetovog rođenja opremaju prostor u kome će dete boraviti različitim nameštajem, opremom i igračkama, određuju spektar boja kojima će dete biti izloženo već od prvih dana života, kao i mogućnosti za istraživanje sveta koji ga okružuje. Na primer, ukoliko odrasli oblikuju porodični prostor tako da se dete u njemu može samostalno kretati i da može dohvatiti svaku igračku koju poželi time mu šalju poruku da veruju u njegove kapacitete i da podržavaju njegovu potrebu za istraživanjem svog okruženja. S druge strane, ukoliko odrasli pristupe uređenju prostora sa pretpostavkom da je bezbednost deteta na prvom mestu oni će se potruditi da mu kretanje u prostoru ograniče na "bezbedne zone". U tom slučaju biće neophodno prisustvo i asistencija odraslog u dečjem istraživanju okruženja. U ovom radu fokus je samo na igračkama kao predmetima za dečju igru, a predstavljeni primer nam ilustruje kako svi materijali kojima je dete okruženo, kao i prakse uređenja prostora mogu biti predmet preispitivanja jer direktno šalju poruku detetu o očekivanjima odraslih po pitanju njegovog ponašanja.

Podržavati dečju igru obezbeđivanjem različitih materijala za igru (u slučaju ovog rada igračaka za decu) znači obezbediti detetu materijale kojima ono može samostalno da "vlada", da ih podigne, uzme u ruke i prenosi u toku igre bezbedno (sve ovo ukazuje na primerenost materijala uzrastu deteta). Važno je da su igračke koje nudimo deci sigurne, odnosno da 
materijali od kojih su sačinjene ne ugrožavaju detetovo zdravlje, da ne postoje oštre ivice koje mogu uzrokovati povredu, ali važno je i da detetu omogućavaju da se oseti moćno i da samostalno istražuje (Krnjaja, 2012b). Svi navedeni kriterijumi važni su za promišljanje kvaliteta igračke iz pedagoške perspektive.

Roditelji kao najznačajnije odrasle osobe u životu deteta su oni koji imaju mogućnost da u najvećoj meri oblikuju uslove za dečji razvoj i učenje, ali imaju i najveću odgovornost u tom pogledu, a načini na koje će to činiti zavise sa jedne strane od društvenih uticaja i sa druge strane od njihovih ličnih iskustava i implicitnih pedagogija (Malovic i Malovic, 2017), tj. uverenja o tome na koji način se deca razvijaju i uče i kako odrasli mogu doprineti tom procesu.

Pitanje odabira igračaka kojima će se deca igrati jeste često direktno povezano sa razmišljanjima odraslih o tome kako da podrže dečji razvoj i učenje. Odabir igračaka danas može biti izazovan poduhvat jer se na tom polju mogu prepoznati snažni marketinški uticaji. Industrija igračaka ulaže najviše sredstava u marketing u odnosu na sve druge industrije čiji su proizvodi namenjeni deci (Piachaud, 2007). Kroz pažljivo oblikovane kampanje do roditelja dopire mnoštvo poruka koje mogu uticati na njihov izbor prilikom kupovine igračke. Veoma je važno da odrasli osveste na koji način prave izbore kada kupuju igračke, jer njihovi izbori direktno utiču i na načine na koje se deca igraju, time što odrasli oblikuju okruženje za dečju igru. Materijali koje deci odrasli nude za igru pokazuju koliko oni podržavaju ili ograničavaju igru, pa tako recimo favorizovanje "poučnih" - edukativnih igračaka šalje se poruka da igračka ne treba da podržava zabavu kod dece već da je bitnije da se igra usmeri ka detetovim postignućima (Krnjaja, 2012b). Nesporno je da deca često igračke koriste na načine koji odstupaju od pretpostavki odraslih, da sama definišu svrhu i namenu igračkama zaobilazeći njihova uputstva, ali to nas ne lišava odgovornosti i uticaja u oblikovanju mogućnosti za dečju igru.

U ovom radu želimo da preispitamo praksu kupovine igračaka za decu jer svi podaci ukazuju na to da industrija igračka nastavlja da raste. Na primer, u Americi je 2013. godine bio primetan rast od 3\% (u industriji koja proizvodi 3,1 bilion dolara profita godišnje) za godinu dana u pogledu toga koliko se igračke kupuju (The Toy Association, 2013, prema: Dauch, Imwalle, Ocasio \& Matz, 2018).Razvoj industrije igračaka može ukazivati i na porast broja igračaka u prosečnom domu, ali postoji dilema da li količina igračaka koju dete poseduje direktno odražava kvalitet okruženja za igru. Ovim istraživanjem želimo da otvorimo pitanje kvaliteta komercijalnih igračaka iz ugla odraslih kao i da preispitamo praksu njihove kupovine, kako bismo istražile da li odrasli kupovinom igračke žele da podrže dečju igru ili postoje druge linije razmišljanja u tom procesu.

\section{Metodološki okvir istraživanja}

Cilj istraživanja opisivanje prakse kupovine igračaka za decu iz ugla odraslih operacionalizovan je kroz sledeće istraživačke zadatke:

1. Opisati povode i učestalost kupovine igračaka za decu od strane odraslih.

2. Predstaviti percepciju odraslih o upotrebnoj vrednosti igračaka koje kupuju u pogledu dužine trajanja i korišćenja igračke.

3. Predstaviti najvažnije kriterijume koji utiču na odabir igračke prilikom kupovine.

4. Preispitati koncept dobre, odnosno kvalitetne igračke iz ugla odraslih. 
Istraživačko pitanje kojim smo se rukovodile u ovom istraživanju bilo je: šta određuje praksu kupovine igračaka za decu? Zanimalo nas je da odgovorimo na pitanje koji su to elementi prakse kupovine igračaka za decu koji utiču na izbor prilikom kupovine igračaka. Izdvojila su se pitanja o povodima za kupovinu igračaka, koja nam ukazuju na to šta motiviše odrasle da se upuste u kupovinu igračaka za decu. Zatim se javlja pitanje odabira same igračke na koji može uticati percepcija onih koji ih kupuju o njihovoj upotrebnoj vrednosti, kao i njihova percepcija o tome šta karakteriše kvalitetnu/dobru igračka. U ovom istraživanju tragale smo i za odgovorom na pitanje koji se to kriterijumi ističu kao najznačajniji prilikom odabira igračke za decu koju odrasli kupuju.

U skladu sa postavljenim ciljem i na osnovu njega operacionalizovanim zadacima istraživanja opredelile smo se da u istraživanju koristimo deskriptivnu istraživačku metodu (Krishnarao, 1961) koja nam omogućava da steknemo uvid u specifičan deo pedagoške stvarnosti koji se odnosi na praksu kupovine igračaka za decu i da pokušamo da ga razumemo. Istraživanje je eksplorativnog karaktera što znači da otvara brojna pitanja koja se mogu dalje preispitivati i nameće teme koje traže produbljivanje i bolje razumevanje.

$\mathrm{U}$ istraživanju smo koristile tehniku anketiranja u okviru koje su učesnici istraživanja popunjavali online upitnik. Forma upitnika koju smo koristile jeste upitnik sa mešovitim tipom pitanja (Mukherji \& Albon, 2015). Upitnik je sadržao: šest pitanja poluotvorenog tipa sa ponuđenim odgovorima i mogućnošću dopisivanja odgovora koji se ne nalazi među ponuđenim; šest pitanja zatvorenog tipa (skale) na koja su učesnici davali odgovor pomoću petostepene skale; dva pitanja otvorenog tipa.

Učesnici ovog istraživanja odabrani su metodom prigodnog uzorkovanja (ibid), a odgovore na pitanja iz online upitnika dalo je 112 učesnika istraživanja. Svi učesnici istraživanja su odrasle osobe koji svedoče o svojim praksama kupovine igračaka iz različitih uloga, stoga smo im najpre postavile pitanje iz koje uloge oni učestvuju i istraživanju. Kako neki od učesnika imaju i više uloga moguće je bilo dati više odgovora. Najveći broj učesnika su roditelji ( $f=80,71,4 \%$ ), među kojima ima i onih koji svedoče o kupovini igračaka za decu i iz uloge roditelja i iz uloge rođaka ili prijatelja ili neke druge uloge. Prikaz njihovih odgovora dat je u Tabeli 1.

Tabela 1. Uloge iz kojih učesnici istraživanja kupuju igračke za decu

\begin{tabular}{|l|l|l|}
\hline Uloga & Broj učesnika & Procenat \\
\hline Roditelj & 80 & $71,4 \%$ \\
\hline Rođaka/rođak & 34 & $30,4 \%$ \\
\hline Prijatelj & 23 & $20,5 \%$ \\
\hline Kuma/kum & 18 & $16,1 \%$ \\
\hline Sestra/brat & 8 & $7,1 \%$ \\
\hline Deda mraz & 8 & $6,3 \%$ \\
\hline Baba/deda & 3 & $2,7 \%$ \\
\hline Ostalo (nastavnik, superjunak, dadilja) & 3 & $3,5 \%$ \\
\hline
\end{tabular}


Obradu podataka dobijenih kroz zatvoreni tip pitanja u upitniku sprovele smo putem deskriptivne statistike (izračunavanje frekvencija i procenata, a pre interpretacije odgovora koristile smo statističke testove (Hi-kvadrat test nezavisnosti, T-testove i ANOVA testove različitih grupa) kako bismo proverile postojanje statističke značajnosti u pogledu nekih uočenih tendencija koje smo proučavale. Hi-kvadrat testovi nezavisnosti korišćeni su za istraživanje postojanja statistički značajne zavisnosti između postavljenih nezavisnih promenljivih: pitanja kome se igračka kupuje (operacionalizovanog kroz 4 grupe odgovora: kupovina svojoj deci, kupovina deci svojih prijatelja/rođaka, kupovina i svojoj i deci svojih prijatelja/rođaka i retke prilike za kupovinu igračaka) i pitanja uloge iz koje se kupuju igračke (operacionalizovano kroz izdvajanje dve grupe učesnika istraživanja - oni koji jesu i oni koji nisu roditelji) i zavisnih promenljivih: povoda za kupovinu igračaka; percepcije o životnom veku, odnosno upotrebnoj vrednosti igračaka koje se kupuju. T-testovi uparenih uzoraka korišćeni su kako bi se utvrdila statistička značajnost percipiranih razlika u pogledu procene u kojoj meri različiti kriterijumi utiču na odabir igračke prilikom kupovine. Daljom analizom putem T-testova uparenih uzoraka (za promenljivu - uloga iz koje se kupuju igračke za decu) i ANOVA testova različitih grupa (za promenljivu kome se kupuju igračke) istraživale smo postojanje statistički značajne razlike između grupa ispitanika u pogledu procene uticaja različitih kriterijuma na odabir igračaka za decu.

U interpretaciji odgovora na pitanja otvorenog tipa opredelile smo se za postupak otvorenog kodiranja koje podrazumeva izdvajanje tema - kategorija za analizu koje se mogu u toku interpretacije proširivati i menjati, ukoliko se uvidi potreba za reorganizacijom kategorija ili za dodavanje novih (Halmi, 2005).

\section{Prikaz rezultata istraživanja}

\section{Povod i učestalost kupovine igračaka za decu od strane odraslih}

Pitanje o tome da li naši učesnici kupuju igračke za decu i kome ih kupuju bilo je pitanje sa mogućnošću davanja višestrukih odgovora. Analizom odgovora izdvojene su 4 grupe učesnika istraživanja: 1) oni koji igračke kupuju uglavnom za svoju decu; 2) oni koji igračke kupuju za decu svojih prijatelja/rođaka; 3) one koji kupuju igračke i za svoju decu i za decu svojih prijatelja/rođaka; 4) one koji retko kupuju igračke. Raspodelu odgovora učesnika dajemo na grafičkom prikazu (Grafikon 1).

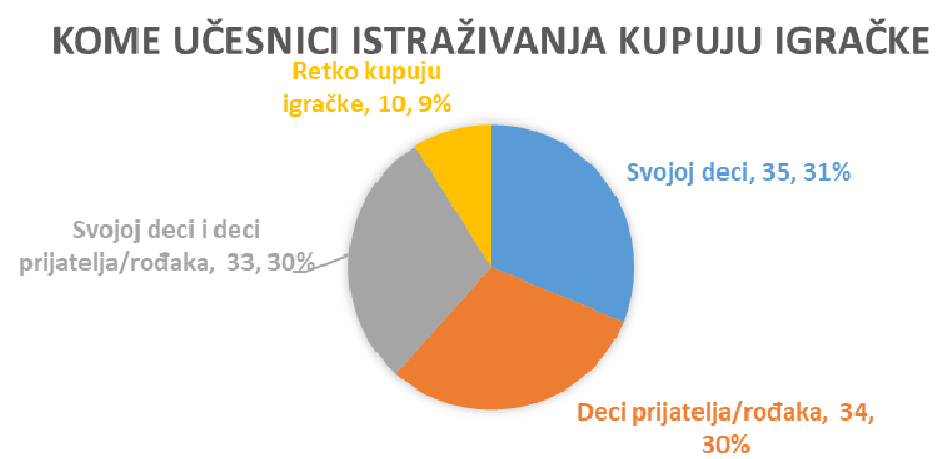

Grafikon 1. Prikaz frekventnosti javljanja ponuđenih odgovora na pitanje 
$\mathrm{Na}$ osnovu predstavljenih odgovora može se zaključiti da u gotovo jednakom procentu učesnici istraživanja igračke kupuju svojoj deci i deci prijatelja/rođaka. U daljoj interpretaciji istraživačkih nalaza težimo razumevanju da li se prakse kupovine dečjih igračaka u nečemu razlikuju onda kada učesnici istraživanja kupuju igračke svojoj deci i kada igračke koje kupuju namenjuju deci rođaka/prijatelja.

Kako bismo otkrile u kojim situacijama učesnici istraživanja najčešće kupuju igračke postavile smo im pitanje sa mogućnošću davanja višestrukih odgovora, jer smo pretpostavile da mnogi među njima kupuju igračke različitim povodom. Kao povod za kupovinu igračaka učesnici najčešće navode dečije rođendane $(f=86,76,8 \%)$, a pored ovog povoda ističe se još $i$ kupovina igračaka kao poklon za praznike $(f=58,51,7 \%)$, kupovina igračaka u drugim specijalnim prilikama susretanja (kada se prvi put sretnemo sa detetom, kada se desi nešto bitno u životu deteta... $)(f=58,51,7 \%)$, na kraju u 50\% $(f=56)$ odgovora koje su davali učesnici istraživanja prepoznajemo da oni kupuju igračke i bez konkretnog povoda, kupuju onda kada vide dobru igračku.

Za potrebe odgovora na pitanje da li se prakse kupovine dečjih igračaka u nečemu razlikuju onda kada kupujemo za svoju i za drugu decu ukrstile smo podatke o tome kome naši učesnici kupuju igračke i u kojim povodima. Hi-kvadrat test nezavisnosti pokazao je statistički značajnu zavisnost između toga kome se igračke kupuju i da li se one: kupuju deci za rođendane (ovde je utvrđena zavisnost na nivou $0,05\left(\chi^{2}=11,040, p=0,012\right)$ i utvrđen je veliki uticaj, $\left.V=0,314\right)$, kupuju deci za praznike (ovde je utvrđena zavisnost na nivou $0,05(\chi 2=10,357, p=0,016)$ i utvrđen je veliki uticaj, $V=0,3$ ); kupuju deci za ostale specijalne prilike (ovde je utvrđena zavisnost na nivou $0,05\left(\chi_{2}=13,007, p=0,004\right)$ i utvrđen je veliki uticaj, $\left.V=0,34\right)$ i kupuju onda kada se vidi dobra igračka $(\chi 2=12,954, p=0,005)$ i utvrđen je veliki uticaj, $V=0,34)$.

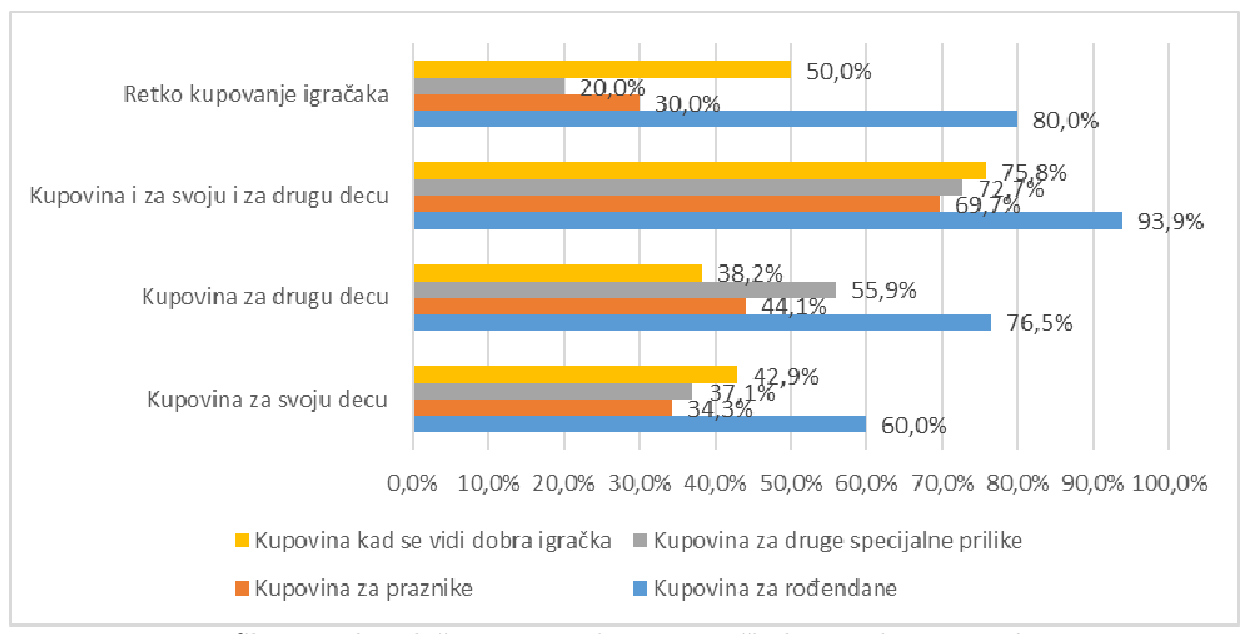

Grafikon 2. Prikaz ukrštanja pitanja kome se igračke kupuju i kojim povodom

Na grafikonu 2 je uočljivo da bez obzira na to da li igračke kupuju svojoj deci ili deci svojih prijatelja/rođaka, rođendani predstavljaju najčešći povod kada učesnici istraživanja kupuju igračke. Kada kupujemo igračke za svoju decu gotovo podjednako im kupujemo i za praznike (34,3\% onih koji kupuju igračke svojoj deci kupuju im ih za praznike, a 37,1\% ih kupuje i za druge specijalne prilike), dok kada kupujemo drugoj deci kao češći povod se ističu druge specijalne 
prilike (55.9\%) u odnosu na praznike (44,1\%). Možemo pretpostaviti da su praznici period u kome postoji tradicija da roditelji deci na poklon kupuju igračke, dok su druge specijalne prilike one u kojima kupujemo igračke tuđoj deci.

Na pitanje "koliko često kupujete igračke za decu" najveći broj učesnika ( $N=34)$ odgovorio je da to čini jednom u 3 meseca. Na drugom mestu po učestalosti odgovora nalaze se oni koji igračke kupuju jednom mesečno $(\mathrm{N}=27)$. To nam ukazuje da preko $60 \%$ učesnika istraživanja igračke kupuje jednom u 3 meseca ili češće.

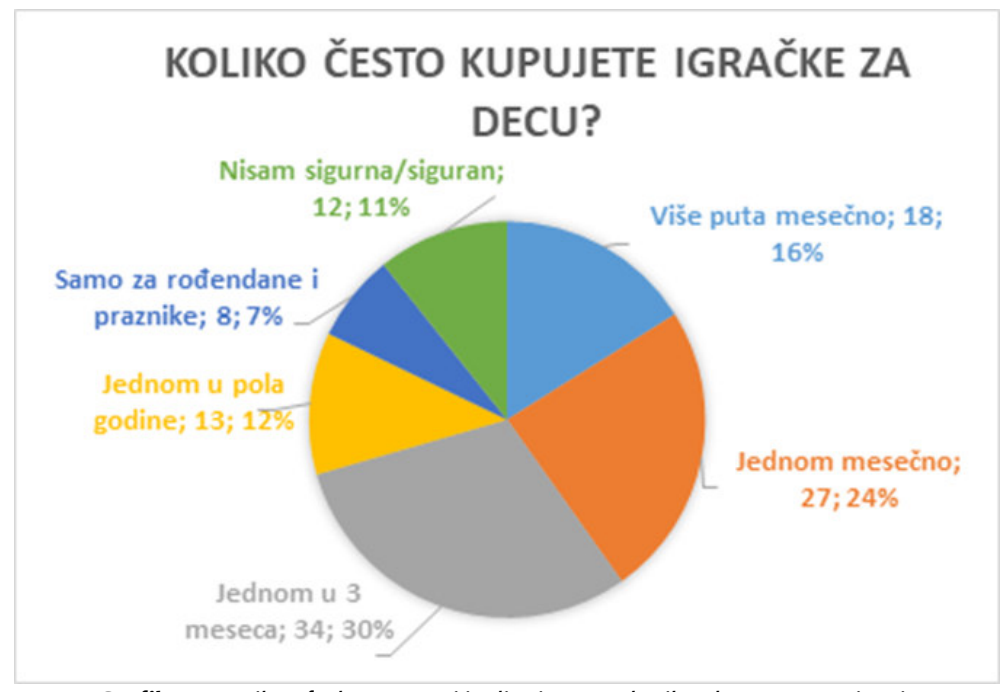

Grafikon 3. Prikaz frekventnosti javljanja ponuđenih odgovora na pitanje

\section{Percepcija odraslih o upotrebnoj vrednosti igračaka koje kupuju u pogledu dužine trajanja i korišćenja igračke}

U okviru ovog istraživačkog zadatka učesnici istraživanja pružili su odgovor na pitanje koji je životni vek igračaka koje kupuju. Preko trećine učesnika naveo je da se igračke koje kupuju nasleđuju, tj. dugo traju i prenose se s generacije na generaciju $(\mathrm{N}=38)$.

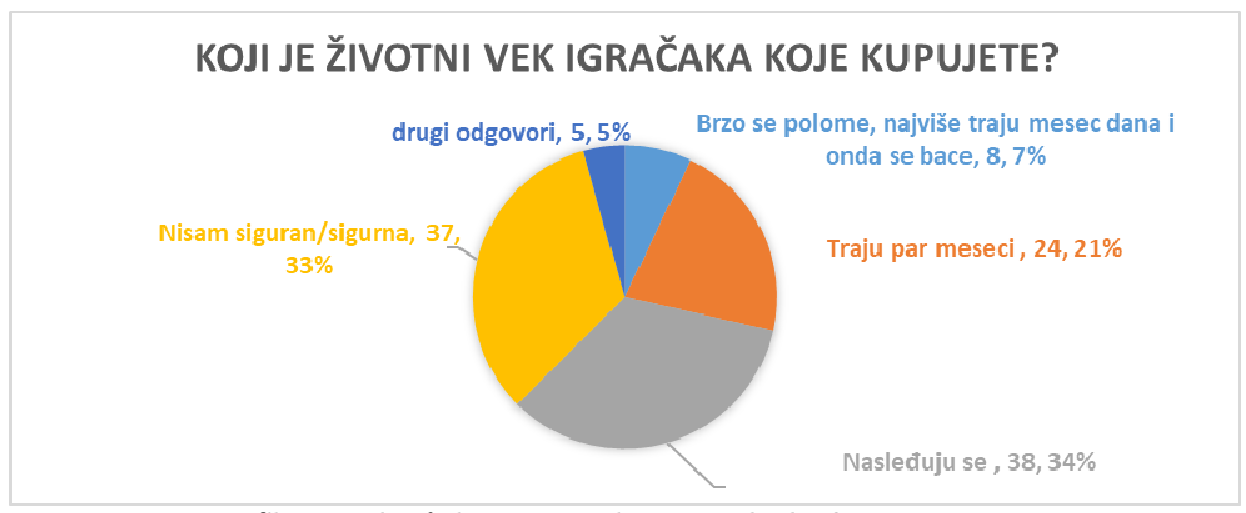

Grafikon 4. Prikaz frekventnosti javljanja ponuđenih odgovora na pitanje 
Kako bismo utvrdile da li postoji veza između roditeljske uloge (da li onaj ko kupuje igračke ima svoju decu) i percepcije učesnika istraživanja o tome koliko ostaju u upotrebi igračke koje se deci kupuju sprovele smo Hi-kvadrat test nezavisnosti koji je pokazao da postoji statistički značajna zavisnost na nivou $0,05\left(\chi^{2}=12,947, p=0,005\right)$ između roditeljske uloge i percepcije 0 životnom veku igračaka koje deci kupuju učesnici istraživanja. Utvrđen je veliki uticaj $(V=0,35)$ uloge roditelja na pomenutu percepciju. Da bismo produbile razumevanje percepcije o životnom veku igračaka koje se deci kupuju sprovele smo još jedan Hi-kvadrat test nezavisnosti u kom smo testirale zavisnost između toga kome se igračke kupuju (svojoj deci, deci prijatelja i/ili rođaka, i svojoj i deci prijatelja i/ili rođaka ili se retko kupuju) i percepcije o životnom veku igračke. Hi-kvadrat test nezavisnosti pokazao je statistički značajnu zavisnost na nivou $0,01\left(\chi_{2}=32,307, p=0,000\right)$ između toga kome se igračke kupuju i percepcije o tome koliko se dugo deca igraju igračkama koje kupuju učesnici istraživanja. Utvrđen je srednji uticaj $(V=0,24)$ uloge iz koje se igračke kupuju na percepciju o životnom veku igračke.

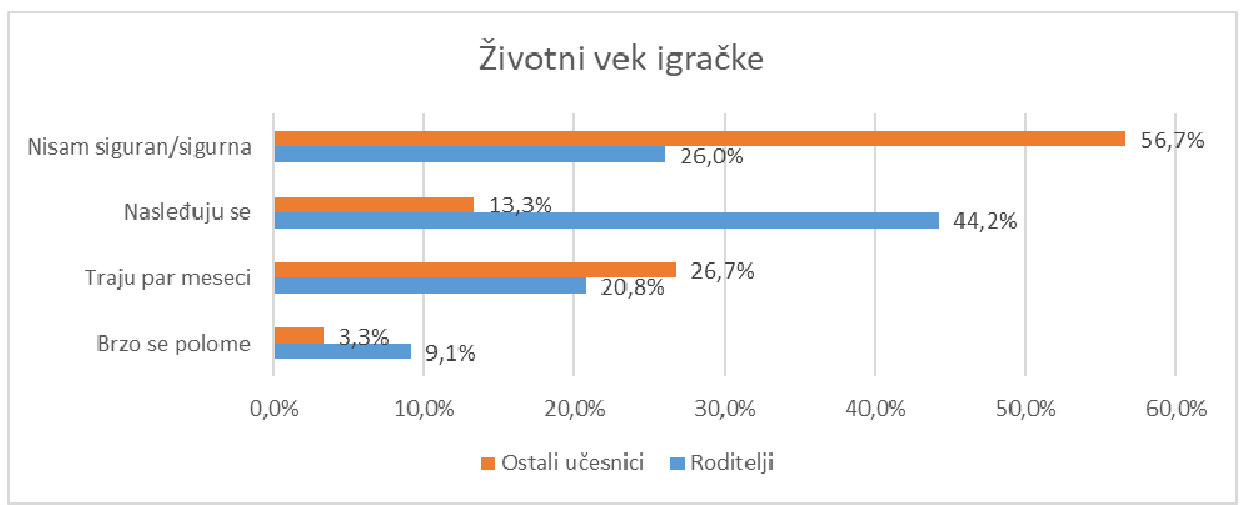

Grafikon 5. Prikaz odnosa roditeljske uloge i percepcije o životnom veku igračke

Podaci na grafikonu 5 nam pokazuju da $44,2 \%$ roditelja ( $N=34$ ) navodi da igračke koje kupuju traju dugo, tj. da se nasleđuju. Interesantan je podatak da najveći procenat učesnika koji spadaju u grupu "ostali" (koji ne učestvuju u istraživanju iz ugla roditelja) nije siguran koji je životni vek igračaka koje kupuju (56,7\%). Ovo možemo razumeti kao posledicu toga da nakon što poklonimo igračku detetu koje nije naše mi nemamo uvid u to na koji način dete koristi tu igračku i koliko dugo je ona u upotrebi. Sa druge strane, kada posmatramo Grafikon 6 koji daje prikaz odnosa kome su igračke namenjene i percepcije o životnom veku igračke vidimo da kada kupujemo igračke svojoj deci onda imamo predstavu koliko one traju (niko od učesnika koji su nam rekli da kupuju igračke svojoj deci nije rekao da nije siguran/sigurna koliko dugo igračka traje), što je logična posledica toga da kupljene igračke ostaju u našem neposrednom okruženju. 


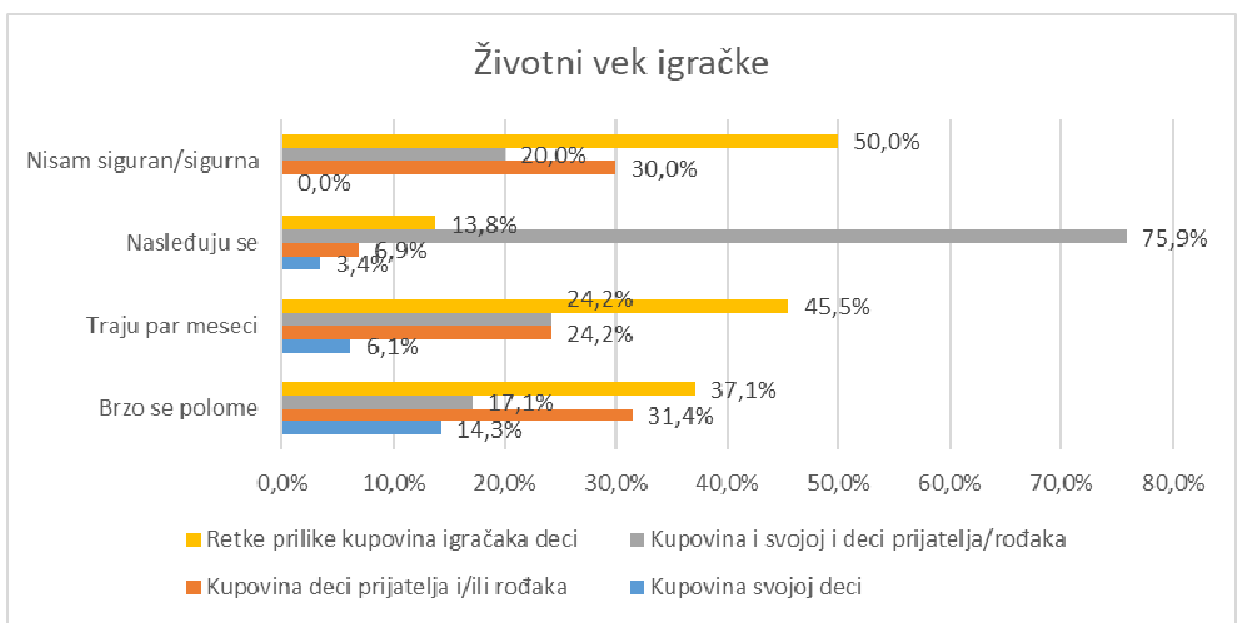

Grafikon 6. Prikaz odnosa kome su igračke namenjene i percepcije o životnom veku igračke

Pored toga koliko dugo igračke traju, odnosno koliko brzo se oštete/polome, pitale smo učesnike istraživanja i to koliko dugo su deci zabavne igračke koje im kupuju, odnosno koliko dugo se deca njima igraju.

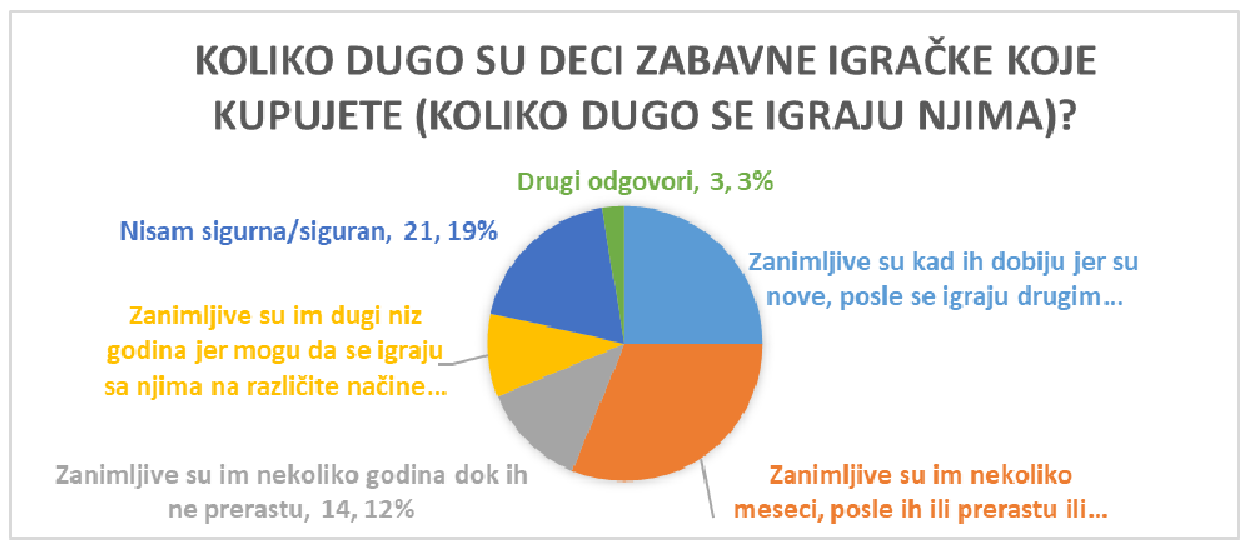

Grafikon 7. Pretpostavka učesnika istraživanja o tome koliko dugo su deci zabavne igračke koje oni kupuju

$\mathrm{Na}$ osnovu prikazanih odgovora učesnika istraživanja možemo zaključiti da se deca konkretnom igračkom najčešće igraju nekoliko meseci (31\%) ili tek kratak period nakon što je dobiju (25\%), a zatim im igračka dosadi i zamenjuju je drugom igračkom. Ovakvi nalazi ukazuju na to da životni vek igračaka i njihovo prisustvo u dečjoj igri ne moraju biti skladu jedno $s$ drugim. Dok najveći procenat učesnika istraživanja navodi da se igračke koje kupuju najčešće nasleđuju (34\%), približno isti procenat učesnika istraživanja ističe da se igračkama koje kupuju deca igraju tek par meseci (31\%).

Sprovele smo još jedan Hi-kvadrat test nezavisnosti kako bismo preispitale da li postoji veza između roditeljske uloge i percepciju o tome koliko dugo su deci zanimljive igračke koje se kupuju, odnosno koliko se dugo njima igraju i test je ponovo pokazao statistički značajnu zavisnost na nivou $0,05\left(\chi^{2}=15,911, p=0,003\right)$ između roditeljske uloge i percepcije o tome 
koliko se dugo deca igraju igračkama koje kupuju učesnici istraživanja. Utvrđen je veliki uticaj $(V=0,38)$ uloge roditelja na pomenutu percepciju. Ovi podaci ukazuju nam na to da ukoliko imamo svoju decu posmatranjem njihovog angažovanja u igri različitim igračkama možemo uočiti koliko dugo se deca igraju određenim igračkama, odnosno možemo da uočimo kada je neka igračka detetu zanimljiva i kada prestaje to da bude.

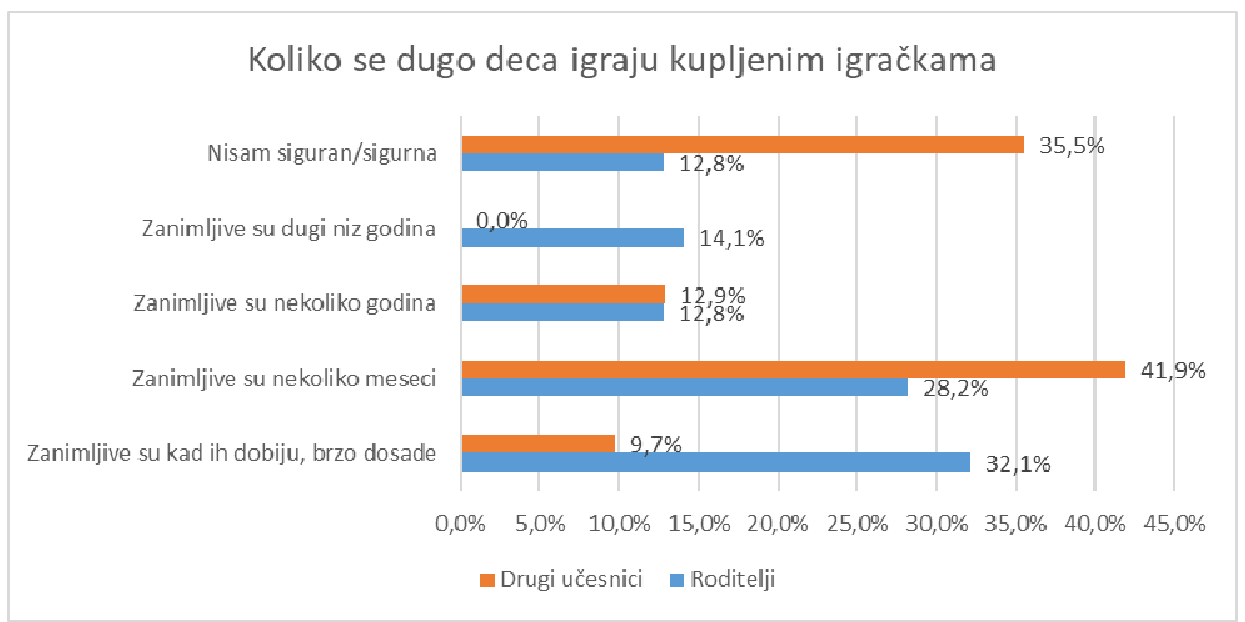

Grafikon 8. Prikaz odnosa roditeljske uloge i percepcije o tome koliko su deci zanimljive kupljene igračke

Kao i na primeru promišljanja o tome koliko dugo kupljene igračke traju dok se ne oštete ili iz nekog drugog razloga odbace, tako i na primeru promišljanja o tome koliko dugo su deci zabavne kupljene igračke pre nego što ih odbace vidimo da se odgovor "nisam sigurna/siguran" javlja u većoj meri kod onih koji nemaju svoju decu. Međutim, dok su nam svi učesnici istraživanja koji jesu roditelji rekli da znaju koliki je životni vek igračke (pre nego što se odbaci) ipak postoji i određeni deo roditelja (12,8\%) koji nisu sigurni koliko dugo su deci zanimljive igračke koje im kupuju. Kako jedan deo roditelja koji su učestvovali u istraživanju kaže da igračke kupuje i svojoj i deci svojih prijatelja/rođaka možemo pretpostaviti da se ovaj deo odgovora može odnositi na nesigurnost kada se igračke kupuju drugoj deci. Sa druge strane, lakše je uočiti kada se igračka baca ili na neki drugi način uklanja iz dečjeg okruženja nego kada neka igračka ostaje u detetovom okruženju, ali nema upotrebnu vrednost jer se dete njome više ne igra.

Dodatni Hi-kvadrat test nezavisnosti koji smo sprovele kako bismo proverile da li postoji zavisnost uloge iz koje se igračke deci kupuju i procene o tome koliko je dugo igračka detetu zabavna pokazao je da ne postoji statistički značajna zavisnost $(\chi 2=20,814, p=0,053)$.

\section{Kriterijumi koji utiču na odabir igračke prilikom kupovine}

Kako bismo stvorile širu sliku o tome šta sve može uticati na izbor igračke najpre smo postavile pitanje otvorenog tipa "Na osnovu čega birate koje igračke kupujete (Šta je Vama posebno važno kada birate igračke)?”. Odgovore na ovo pitanje analizirale smo tehnikom otvorenog kodiranja i u nastavku prikazujemo izdvojene kategorije odgovora. 
Tabela 2. Kodirani odgovori na pitanje Na osnovu čega birate igračke?

\begin{tabular}{|l|l|l|}
\hline Kategorija & Frekventnost & Procenat \\
\hline Detetu je zanimljiva & 47 & $41,2 \%$ \\
\hline Podstiče dečji razvoj i učenje & 27 & $24,1 \%$ \\
\hline Kvalitetna - otporna na lomljenje & 21 & $18,8 \%$ \\
\hline Podržava razvoj dečje kreativnosti & 14 & $12,5 \%$ \\
\hline Transformativna - višefunkcionalna & 14 & $12,5 \%$ \\
\hline Prilagođena uzrastu & 11 & $9,8 \%$ \\
\hline Prirodni i ekološki materijali & 9 & $8 \%$ \\
\hline Estetski dobro oblikovana & 6 & $5,4 \%$ \\
\hline Bezbedna & 6 & $5,4 \% \%$ \\
\hline Cena & 6 & $5,4 \%$ \\
\hline Proizvođač & 1 & $<5 \%$ \\
\hline
\end{tabular}

Na osnovu odgovora iz Tabele 2 možemo zaključiti da su pojedini učesnici navodili više kriterijuma prema kojima biraju igračke, a da je najčešći kriterijum da je to igračka koja je detetu zanimljiva ( $f=47,41,2 \%$ odgovora). $U$ ovom istraživanju se nismo dalje bavile pitanjem zanimljive igračke iz ugla deteta, te se ne može izvesti zaključak da li je to igračka koja je trenutno popularna među decom, koja je u skladu sa detetovim iskazanim interesovanjima, ili je u pitanju neki drugi opis ovog kriterijuma. Ali ono što mogu biti implikacije za neka buduća istraživanja jesu neki od opisa ovog kriterijuma od strane učesnika istraživanja: "Da detetu bude zanimljiva i da je to ono što su oni želeli"; "Da su u trendu"; "Da su drugačije i zanimljive"; "Šta dete trenutno interesuje".

Kako bismo procenile šta mogu biti faktori koji utiču na odabir igračke prilikom kupovine, nakon pitanja otvorenog tipa postavile smo ponovo pitanje "Šta vam je važno kada birate igračke" ali ovoga puta smo dale 6 različitih kriterijuma koje smo, na osnovu informacija koje proizvođači igračaka najčešće ističu u okviru deklaracija i/ili na pakovanju procenile da mogu biti značajni za odluku o tome koja će se igračka kupiti:

1) zdravstvena ispravnost i bezbednost igračke;

2) da je igračka načinjena od prirodnih i ekoloških materijala;

3) da igračka podržava kreativnosti kod dece;

4) dizajn igračke;

5) proizvođač igračke;

6) cena igračke.

Učesnici su mogli za svaku od kategorija da daju odgovor na petostepenoj skali u zavisnosti od toga u kojoj meri predstavljena karakteristika bitno utiče na njihov izbor. Podržavanje 
kreativnosti izdvojilo se kao najznačajniji kriterijum u odabiru igračke $(M=4,73, S d=0,667)$ dok se kao najslabije ocenjen kriterijum - onaj koji najmanje utiče na odabir igračke izdvaja proizvođač igračke $(M=3,03, S d=1,057)$. Da bismo utvrdile statističku značajnost razlika u prosečnim vrednostima za svaku od 6 ponuđenih kategorija, sprovele smo i seriju T-testova uparenih uzoraka (ukupno 15 parova je testirano - ukrštanjem svih 6 kategorija međusobno) koja je pokazala da su razlike koje su primetne u pogledu izračunatih prosečnih vrednosti jednim delom jesu statistički značajne, dok neke od razlika nisu.

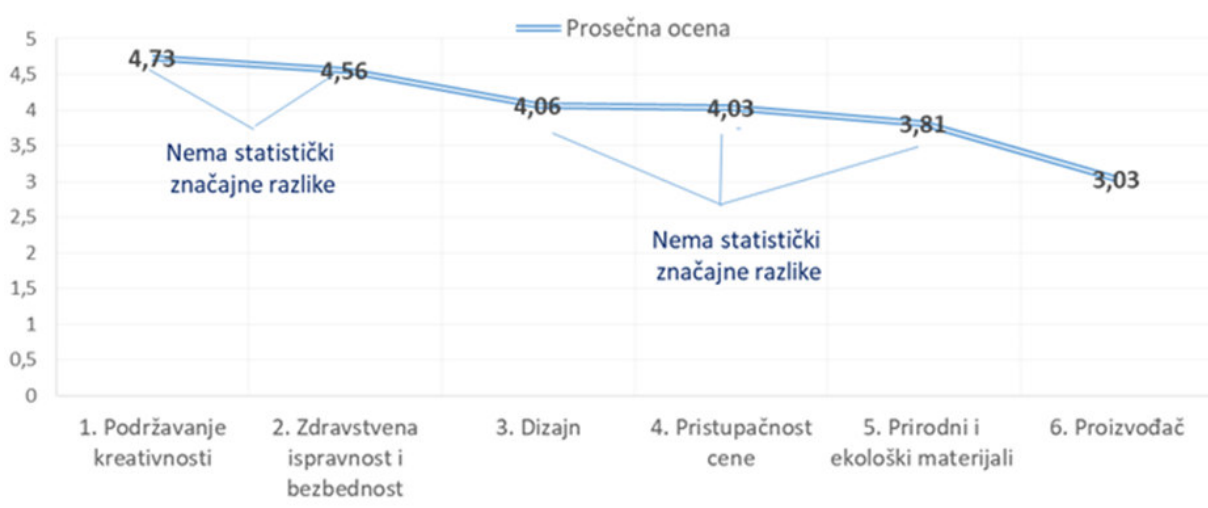

Grafikon 9. Prikaz statističke značajnosti utvrđenih razlika između izdvojenih kriterijuma koji utiču na odabir igračke

Pokušale smo da utvrdimo da li se ocene učesnika istraživanja o tome šta utiče na njihov izbor prilikom kupovine igračaka razlikuju u odnosu na to da li o ovim karakteristikama promišljaju učesnici koji imaju svoju decu ili oni koji nemaju. Sprovele smo seriju T-testova nezavisnih uzoraka u kojima su jednu grupu činili roditelji $(\mathrm{N}=80)$ dok su drugu grupu činili učesnici istraživanja koji nisu roditelji $(\mathrm{N}=32)$ i pokazalo se da ne postoji statistički značajna razlika u tome kako na pitanja o kriterijumima koji mogu uticati na odabir igračke odgovaraju ove dve grupe učesnika. Takođe smo testirale da li postoji razlika u odgovorima sa 6 pitanja predstavljenih u vidu petostepene skale između tri grupe učesnika na osnovu toga kome oni igračke kupuju. Podelile smo uzorak na četiri grupe: oni koji kupuju igračke za svoju decu $(\mathrm{N}=35)$ oni koji igračke kupuju i za svoju i za decu svojih prijatelja/rođaka $(\mathrm{N}=34)$, oni koji igračke kupuju za decu svojih prijatelja/rođaka $(\mathrm{N}=34)$ i onih koji retko kupuju igračke za decu $(\mathrm{N}=10)$ zatim smo sprovele seriju jednofaktorskih ANOVA testova različitih grupa. Pokazalo se da ni među ovim grupama učesnika ne postoji statistički značajna razlika u pogledu toga kako odgovaraju na 6 pitanja o kriterijumima koji mogu uticati na izbor igračke prilikom kupovine. Zbog ovih saznanja procene o značaju određenih karakteristika za odabir igračke koja se kupuje prikazujemo zbirno.

Na grafiku koji je dat ispod (Grafikon 10) može se uočiti da se kao dve ključne karakteristike koje utiču na izbor prilikom kupovine mogu izdvojiti podrška dečjoj kreativnosti i zdravstvena ispravnost $\mathrm{i}$ bezbednost. Rezultati T-testova uparenih uzoraka na paru koji čine ova dva kriterijuma pokazala je da u vrednostima odgovora ne postoji statistički značajna razlika, pa možemo zaključiti da se ova dva kriterijuma podjednako mogu smatrati najvažnijim kriterijumima za odabir igračke. Prilikom odgovaranja na ova dva pitanja niko od učesnika istraživanja nije rekao da ove karakteristike ne utiču na njihov izbor ili da veoma malo utiču, 
već su gotovo svi odgovori bili usmereni na to da ove karakteristike u velikoj meri utiču na njihov izbor. Pomenuta dva kriterijuma pokazuju se kao statistički značajnija od svih ostalih kriterijuma.

Tri kriterijuma: dizajn, pristupačnost cene i materijali od kojih je igračka utiču manje na odabir igračke nego prethodno pojašnjena dva kriterijuma, a između ova tri kriterijuma u pogledu toga u kojoj meri utiču na izbor igračke ne postoji statistički značajna razlika. Možemo reći da su ova tri kriterijuma nešto što neće biti presudno za odabir igračke.

Na kraju, jedina karakteristika koja se izdvojila po broju odgovora koji ukazuju na to da ne utiče bitno na izbor igračke jeste pitanje proizvođača (čak 37 učesnika reklo je da pitanje ko proizvodi igračku ne utiče ili izuzetno slabo utiče na njihov izbor igračke). T-testovi uparenih uzoraka pokazali su da se ova karakteristika statistički značajno razlikuje od svih ostalih u pogledu procene na to koliko će uticati na izbor prilikom kupovine igračke pa možemo reći da je ona najzanemarljivija karakteristika kada je reč o donošenju odluke koju ćemo igračku kupiti.

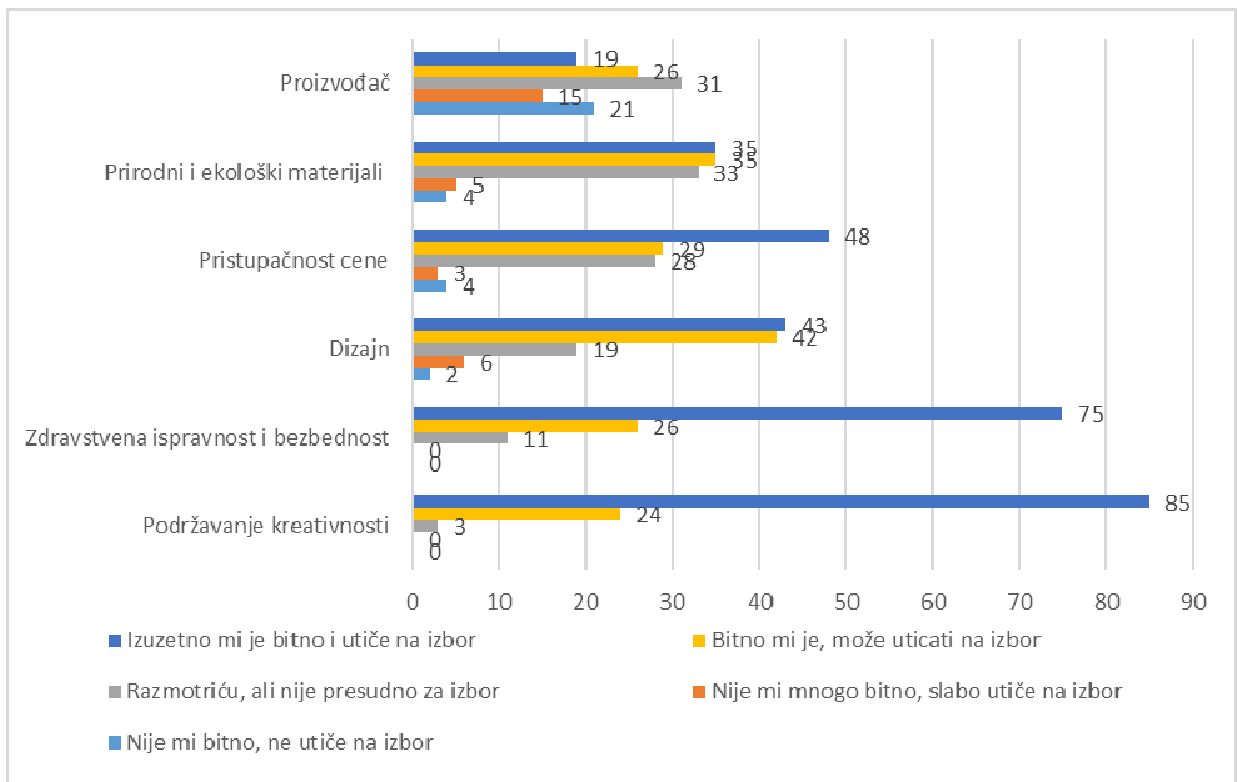

Grafikon 10. Prikaz odgovora na pitanja sa skale

Analizirajući sve odgovore u okviru ovog istraživačkog zadatka možemo zaključiti da nam je otvoreno pitanje o kriterijumima izbora igračke kao najzastupljeniji kriterijum izdvojilo onaj koji nije prikazan u ponuđenim skalama. Kategorija "da je igračka detetu zanimljiva" se izdvojila kao najznačajnija pri izboru igračke i kao takva zavređuje dalje istraživanje, kako bi se utvrdilo njeno značenje.

\section{Koncept dobre igračke iz ugla odraslih}

U okviru ovog zadatka želele smo da istražimo šta je po kriterijumima odraslih dobra, tj. kvalitetna igračka. Učesnici istraživanja su u okviru pitanja otvorenog tipa imali mogućnost da opišu dobru igračku iz svog ugla. U Tabeli 3 prikazani su njihovi kodirani odgovori. 
Tabela 3. Odgovori na pitanje "Šta je za vas dobra igračka"

\begin{tabular}{|l|l|l|}
\hline Kategorija & Frekventnost & Procenat \\
\hline Detetu je zanimljiva & 33 & $29,5 \%$ \\
\hline Podržava razvoj dečje kreativnosti & 31 & $27,7 \%$ \\
\hline Podstiče dečji razvoj i učenje & 23 & $20,5 \%$ \\
\hline Transformativna - višefunkcionalna & 16 & $14,3 \%$ \\
\hline Otporna na lomljenje & 12 & $10,7 \%$ \\
\hline Ekološka & 4 & $<5 \%$ \\
\hline Bezbedna & 4 & $<5 \%$ \\
\hline Lego kocke & 3 & $<5 \%$ \\
\hline
\end{tabular}

Na osnovu prikazanih odgovora možemo primetiti da se kao najučestaliji kriterijum dobre igračke iz ugla učesnika istraživanja izdvaja to da je igračka detetu zanimljiva, što se izdvaja i kao najučestaliji kriterijum pri donošenju odluke koju će igračku kupiti učesnici istraživanja. I u situacijama kupovine igračaka i u opisu dobre igračke, odrasli smatraju da je važno da igračka bude detetu zanimljiva. Kriterijum da je igračka detetu zanimljiva pronašle smo u odgovorima na pitanje "Šta je za vas dobra igračka" koji sa jedne strane ukazuju na to da igračka najpre treba da zainteresuje dete, poput: "Svaka koju dete ne odbija da koristi"; "Ona koja kod dece izaziva interesovanje"; "Igračka koja će obradovati dete"; "Ona koju dete stalno traži". S druge strane jedan deo odgovora na ovo pitanje ukazuje da je dobra igračka ona koja je detetu zanimljiva duži vremenski period: “Ona koja zaokupi detetu pažnju duže vreme”; "Igračka koja će animirani dete i kojoj će posvetiti pažnju".

Na drugom i trećem mestu kriterijuma dobre igračke nalaze se oni opisi koji su vezani za njen doprinos dečjem razvoju i učenju, ili specifično razvoju kreativnosti kod dece. To su odgovori poput: “Igračka koja će detetu držati pažnju, sa kojom se može ponešto naučiti, koja se neće polomiti za 3 dana i koja neće završiti sa svim ostalim u kutiji za igračke”.

\section{Zaključna razmatranja}

Ovim istraživanjem težilo se ukrštanju savremenih teorijskih postavki o shvatanju dečje igre i detinjstva sa perspektivom odraslih o praksi kupovine igračaka za decu kao najzastupljenijih predmeta za igru u odrastanju dece danas.

Istražujući prakse kupovine igračaka za decu iz perspektive odraslih uvidele smo da odrasli često kupuju igračke za decu (60\% učesnika istraživanja ih kupuje jednom u tri meseca ili češće) i da su najčešći povodi za kupovinu igračka dečiji rođendani, ali se igračke kupuju i kao pokloni za praznike i druge specijalne prilike kada se okupljamo. Uzimajući u obzir učestalost kupovine i povode o kojima svedoče učesnici našeg istraživanja možemo reći da se igračke najčešće kupuju kao pokloni i to više uzimajući u obzir povod okupljanja nego promišljanje o kvalitetu 
same igračke (svega petina odgovora učesnika istraživanja ukazuje da oni igračku kupuju onda kada vide "dobru igračku”, dok se u većoj meri igračka kupuje povodom proslava i okupljanja susreta sa decom).

Ovakvi podaci ukazuju da iako smo u teorijskom delu rada pošle od pretpostavke da odrasli imaju jasne predstave o ulozi igračaka u detetovom razvoju i učenju, ove predstave mogu biti u senci izgrađenih rituala oko prakse kupovine igračaka. Tako potreba odraslog da kupovinom određene igračke doprinese dečjem razvoju i učenju najčešće nije primarni motiv pri kupovini. Pedagoške implikacije koje proizilaze iz ovih uvida ukazuju na potrebu za preispitivanjem značenja i značaja koje odrasli pridaju igračkama, kako bi se osnažili u razumevanju uloge igračaka u procesima dečjeg razvoja i učenja.

U odgovorima učesnika istraživanja primetile smo tendenciju onih koji imaju svoju decu da igračke koje kupuju budu dugotrajne - da se nasleđuju (44,2\% učesnika istraživanja koji su roditelji kažu da se igračke koje kupuju nasleđuju, dok svega $13,3 \%$ onih koji nisu roditelji daju ovaj odgovor). Veoma važan uvid za neka buduća istraživanja može biti to što su gotove igračke deci uglavnom kratko zanimljive - najčešće nekoliko meseci ili tek neko kratko vreme nakon kupovine ( $56 \%$ učesnika kaže da deci igračke prestaju da budu zanimljive nakon par meseci).

Velika učestalost kupovine igračaka može voditi do toga da manje promišljamo o njihovom životnom veku, pa dolazi do toga da deca poseduju veliki broj igračka ali da se samo manjim brojem često igraju. Ovo može biti i jedan od uzroka zbog čega su učesnici ovog istraživanja iz grupe roditelja naveli da teže kupovini igračaka koje će se nasleđivati a ne bacati ili odbacivati posle kratkog vremena upotrebe.

Za učesnike istraživanja ključni kriterijum na osnovu koga definišu koncept "dobre igračke” ali i biraju igračke za decu je "da je igračka detetu zanimljiva”. Važno je napomenuti da u okviru pitanja zatvorenog tipa (skale) ova kategorija nije bila ponuđena, a kako se u okviru pitanja otvorenog tipa izdvojila kao najzastupljenija, ovo može predstavljati značajnu implikaciju za buduća istraživanja, u kojima bi bio analiziran koncept i značenje igračke koja je detetu zanimljiva.

U preispitivanju koncepta dobre igračke naišle smo i na podatak da odrasli cene kada prepoznaju potencijal da igračka podržava dečju kreativnost $(27,7 \%)$, što je drugi bitan kriterijum koji se izdvaja odmah nakon toga da je detetu zanimljiva (29,5\%). Pretpostavljamo da se podrška dečjoj kreativnosti povezuje sa tim da takve igračke deci budu duže vremena zanimljive i ne odbacuju se lako kao one koje detetu dosade jer nisu dovoljno inspirativne.

Rezultati ovog istraživanja ukazuju da je praksa kupovine igračaka u skladu sa konzumerističkim trendovima (kupovina velikog broja predmeta i njihova kratkotrajna upotreba). A kako Miliša i Spasenovski (Miliša i Spasenovski, 2017) ističu da je tema konzumerizma na marginama interesa pedagoških istraživanja, ovi nalazi mogu biti značajni za pokretanje budućih istraživanja kojima bi se produbilo razumevanje ove teme. 


\section{Literatura}

Bergen, D. (2018). The Role of Toys in Promoting Children's development (1-11). In: D. Bergen (ed). The Handbook of Developmentally Appropriate Toys. Rowman \& Littlefield Publishers.

Celebi Oncu, E. \& Unluer, E. (2010). Preschool children's using of play materials creatively. Procedia Social and Behavioral Sciences, 2, 4457-4461.

Cook, D. T. (2007). The disempowering empowerment of children's consumer "choice": Cultural discourses of the child consumer in North America. Society and Business Review2(1), 37-52.

Cross, G. (2004). The Cute and the Cool: Wondrous Innocence and Modern American Children's Culture. Oxford University Press.

Dauch, C., Imwallle, M., Oscario, B. \& Metz, A.E. (2018). The influence of the number of toys in the environment on toddlers' play, Infant Behavior and Development, 50, 78-87.

DCSF \& DCMS (2007). The impact of the Commercial World on Children's Wellbeing. Report of an Independent Assessment for the Department of Children, Schools and Families and the Department for Culture, Media and Sport. Nottingham: DCSF Publications. PDF.

Gross, G. (1997). Kids' Stuff: Toys and the Changing World of American Childhood. Cambridge: Harvard University Press.

Halmi, A. (2005). Strategije kvalitativnih istrazivanja u primenjenim drustvenim znanostima, Zagreb: Nukada Slap.

Kline, S. (1993). Out of the Garden. Toys, TV, and Children's Culture in the Age of Marketing. London: Verso.

Korsvold T. (2010) Proper Toys for Proper Children: A Case Study of the Norwegian Company A/S Riktige Leker (Proper Toys) (31-46). In: Buckingham D., Tingstad V. (eds) Childhood and Consumer Culture. Studies in Childhood and Youth. Palgrave Macmillan, London. https://doi.org/10.1057/9780230281844_3

Krisnarao, B. (1961). The Descriptive Method in Social Research. Sociological Bulletin, 10(2), 4652.

Krnjaja, Z. (2012a). Igra kao susret: koautorski prostor u zajednickoj igri dece i odraslih. Etnoantropoloski problemi, 7(1), 251-278.

Krnjaja, Z. (2012b). Igra na ranim uzrastima. U A. Baucal, Standardi za razvoj i ucenje dece ranih uzrasta u Srbiji (str. 113-133). Beograd: Institut za psihologiju Filozofskog fakulteta i UNICEF.

Malovic, M. (2019). Pedagoske implikacije komercijalizacije igralista za decu ranog uzrasta u gradu. Nastava i vaspitanje, 68(1), 51-70.

Malovic, M. \& Malovic, S. (2017). Parent's perspective on the quality of kindergarten. Research in pedagogy, 7(2), 200-220.

Marjanovic, A. (1979). Stvaralastvo, igra i vaspitanje predskolskog deteta. Predskolsko dete 1-2, 3-33.

McNeal, J. (2000). Children as Consumers of Commercial and Social Products. Washington DC: Pan American Health Organization. Health Promotion and Protection Division.

Milsa, Z. i Spasenovski, N. (2017). Konzumerizam i pedagoske implikacije. Mostariensia: casopis za drustvene i humanisticke znanosti, 21(2), 69-93.

Pavlovic Breneselovic, D. \& Krnjaja, Z. (2016). Discourses on Gender in Early Childhood Education and Care (ECEC) Setting: Equal in Being Discriminated. Journal of Pedagogy, Vol. 7, No. 2, 51-79. 
Petrovic, J. (2015). Intelektualno i emocionalno vaspitanje u reformnoj pedagogiji sa pocetka 20. veka - aktuelnost izvornih shvatanja (doktorska disertacija). Novi Sad: Filozofski fakultet

Piachaud, D. (2007). Freedom to bi a Child: Commercial Pressures on Children. London: CASE London School of Economics.

Saton-Smit, B. (1989). lgračke i kultura, Beograd: Zavod za udžbenike i nastavna sredstva.

Williams, Z. (2007). Commercialization of Childhood. London: Compas.

\section{Biografske note:}

Milijana Lazarević je asistent na Visokoj školi strukovnih studija za vaspitače "Mihailo Palov" u Vršcu i doktorand na Katedri za predškolsku pedagogiju Filozofskog fakulteta u Beogradu. Trener je i mentor u procesu implementacije novih Osnova predškolskog programa "Godine uzleta" u okviru projekta Inkluzivno predškolsko vaspitanje i obrazovanje.

Marija Malović je asistent na Visokoj školi za obrazvanje vaspitača „Mihailo Palov“ u Vršcu. Doktorand je na katerdi za pedagogiju Filozofskog fakulteta Univerziteta u Beogradu. Angažovana je u ulozi trenera i mentora na projektu Ministarstva prosvete, nauke i tehnološkog razvoja i UNICEF-a: „,Razvoj i primena programa izgradnje kapaciteta u sklopu podrške u primeni novih Osnova programa predškolskog vaspitanja i obrazovanja u Srbiji“. 